\title{
Pengaruh Penerapan Total Quality Management, Motivasi Kerja dan Komitmen Organisasi terhadap Kinerja Manajerial
}

\section{Firazzahran Naila Badzaly*}

Prodi Akuntansi, Fakultas Ekonomi dan Bisnis, Universitas Islam Bandung, Indonesia.

*firazzahrann@gmail.com

\begin{abstract}
The survival of the company is determined by good managerial skills. The increasing managerial performance of a company, the company's goals can be achieved. In carrying out its activities, PT Pos Indonesia Majalengka Regency needs to implement total quality management, work motivation and high organizational commitment so that managerial performance can increase. The purpose of this study was to determine the effect of implementing total quality management, work motivation, and organizational commitment on managerial performance at PT Pos Indonesia in Majalengka Regency. The research method is verification research, and the approach is quantitative. The data of this research is sourced from primary data. The method of collecting data using a questionnaire distributed to the managers of PT Pos Indonesia Majalengka Regency. The sampling technique used is non-probability sampling, with purposive sampling. This research uses multiple regression analysis method. The results show that there is an effect of implementing total quality management on managerial performance, there is an effect of work motivation on managerial performance, there is an influence of organizational commitment on managerial performance.
\end{abstract}

Keywords: Implementation of Total Quality Management, Managerial Performance, Organizational Commitment, Work Motivation

\begin{abstract}
Abstrak. Kelangsungan hidup perusahaan ditentukan oleh kemampuan manajerial yang baik. Semakin meningkatnya kinerja manajerial suatu perusahaan maka tujuan perusahaan dapat tercapai. Dalam melaksanakan kegiatannya PT Pos Indonesia Kabupaten Majalengka perlu penerapan total quality management, motivasi kerja serta komitmen organisasi yang tinggi sehingga kinerja manajerialnya dapat meningkat. Dilakukannya penelitian ini bertujuan untuk mengetahui pengaruh penerapan total quality management, motivasi kerja, dan komitmen organisasi terhadap kinerja manajerial pada PT Pos Indonesia di Kabupaten Majalengka. Adapun metode penelitiannya yaitu penelitian verifikatif, dan pendekatannya secara kuantitatif. Data penelitian ini bersumber dari data primer. Adapun metode mengumpulkan data menggunakan kuesioner yang disebarkan kepada para manajer PT Pos Indonesia Kabupaten Majalengka. Teknik pengambilan sampel yang digunakan yakni Non probability sampling, dengan purposive sampling. Penelitian ini menggunakan metode analisis regresi berganda. Hasil menunjukkan terdapat pengaruh penerapan total quality management terhadap kinerja manajerial, terdapat pengaruh motivasi kerja terhadap kinerja manajerial, terdapat pengaruh komitmen organisasi terhadap kinerja manajerial.
\end{abstract}

Kata Kunci: Kinerja Manajerial, Komitmen Organisasi, Motivasi Kerja, Penerapan Total Quality Management 


\section{A. Pendahuluan}

Untuk mempertahankan kelangsungan hidup perusahaan dapat melakukan efisiensi, meningkatkan kualitas serta kinerja manajerial perusahaan, dalam persaingan bisnis yang semakin ketat. Kinerja manajerial adalah hasil proses kegiatan manajerial secara efektif yang dimulai dengan proses merencanakan, melaksanakan, administrasi, laporan pertanggung jawaban, pembinaan dan juga pengawasan. (Dewi dan Ningsih, 2020).

Pada kenyataannya kinerja manajerial suatu perusahaan masih belum memberikan kinerja yang baik, seperti yang terjadi pada PT Garuda Indonesia, kinerja manajemen dikatakan buruk. Ketua Harian Sekarga Tomy Tampatty (2018) mengungkapkan karyawan mengancam akan mogok kerja dikarenakan hubungan industrial perusahaan dengan karyawan yang tidak kondusif, dan keluhan konsumen terkait seringnya pembatalan maupun penundaan penerbangan. Adapun kegagalan manajemen antara lain, kegagalan dalam perubahan sistem penjadwalan, Jabatan Direktur Kargo dinilai tidak diperlukan karena sebelumnya unit kargo hanya dipimpin oleh pejabat setingkat Vice President dan kinerja direktorat ini tidak mengalami peningkatan dan hanya membuang biaya organisasi, peningkatan pendapatan usaha penjualan tiket penumpang tidak mampu mengimbangi beban usaha karena ketidakmampuan Direktur Marketing dan IT daIam membuat strategi penjualan produk, Direktur Personalia banyak mengeluarkan peraturan perusahaan yang bertentangan dengan Perjanjian Kerja Bersama (PKB) tanpa berunding dengan serikat pekerja, sehingga menimbulkan perselisihan dan berakibat pada suasana kerja yang tidak kondusif sehingga dapat berdampak buruk pada kinerja manajemennya (Tomy Tampatty, 2018).

Perusahaan dapat menghasilkan kinerja manajerial yang baik, dengan menerapkan upaya terus menerus, dalam hal pengembangan kualitas. Salah satu strategi manajemen yang berfokus pada kualitas yaitu penerapan Total Quality Management, yang merupakan cara yang terbaik. Total Quality Management merupakan suatu pendekatan dalam menjalankan usaha yang mencoba untuk memaksimumkan daya saing organisasi melalui perbaikan terus menerus atas produk, jasa, manusia, proses, dan lingkungannya (Tjiptono dan Diana, 2003: 3). Perusahaan mampu melakukan persaingan, dengan menghasilkan produk maupun jasa yang memiliki kualitas terbaik. Perusahaan-perusahaan mulai menerapkan Total Quality Management karena dianggap mampu meningkatkan kinerja manajerialnya (Triamelia, dkk., 2015).

Selain penerapan TQM, yang dapat meningkatkan kinerja manajerial yaitu motivasi kerja. Motivasi kerja begitu penting untuk para pimpinan, manajer, dan pegawai. Dengan memiliki motivasi kerja yang tinggi maka dalam melakukan pekerjaannya akan bersemangat, sehingga tujuan yang diinginkan tercapai dengan efektif (Nisa dan Sapari, 2017). Motivasi kerja adalah daya pendorong seseorang untuk mau dan rela menggerakkan kemampuan dalam rangka pencapaian tujuan dan sasaran perusahaan yang telah ditentukan sebelumnya (Sondang Siagian, 2008: 138). Untuk itu, motivasi penting karena dapat mendorong individu agar memiliki antusias dan lebih giat dalam bekerja, sehingga hasil optimal dan maksimal dapat tercapai (Hasibuan, 2020: 141).

Selain penerapan TQM dan motivasi kerja, komitmen organisasi juga memberikan peningkatan pada kinerja manajerial. Seseorang yang mempunyai ikatan emosional terhadap organisasinya dapat memicu tumbuh komitmen organisasional sehingga berusaha untuk mencapai tujuan yang ditetapkan. Rendahnya komitmen organisasi menjadi salah satu kendala yang dapat timbul dalam suatu perusahaan. Komitmen yang rendah dapat berdampak negatif bagi perusahaan sehingga dapat menurunkan produktifitas, kualitas kerja serta berdampak negatif pada kinerja manajerial (Juwita dan Kusumaningrum, 2019).

Dengan melakukan penerapan TQM, motivasi kerja, komitmen organisasi dapat membantu kinerja manajerial suatu perusahaan meningkat.

Bersumber pada latar belakang yang telah diuraikan diatas, maka dirumuskan masalah dalam penelitian ini sebagai berikut:

1. Apakah terdapat pengaruh penerapan total quality management terhadap kinerja manajerial pada PT Pos Indonesia (Persero) di Kabupaten Majalengka? 
2. Apakah terdapat pengaruh motivasi kerja terhadap kinerja manajerial pada PT Pos Indonesia (Persero) di Kabupaten Majalengka?

3. Apakah terdapat pengaruh komitmen organisasi terhadap kinerja manajerial pada PT Pos Indonesia (Persero) di Kabupaten Majalengka?

Adapun tujuan dilakukannya penelitian ini adalah sebagai berikut:

1. Untuk mengetahui pengaruh penerapan total quality management terhadap kinerja manajerial pada PT Pos Indonesia di Kabupaten Majalengka.

2. Untuk mengetahui pengaruh motivasi kerja terhadap kinerja manajerial pada PT Pos Indonesia di Kabupaten Majalengka.

3. Untuk mengetahui pengaruh komitmen organisasi terhadap kinerja manajerial pada PT Pos Indonesia di Kabupaten Majalengka.

\section{B. Metodologi Penelitian}

Objek penelitian pada penelitian ini adalah penerapan total quality management, motivasi kerja, komitmen organisasi dan kinerja manajerial. Sumber data yang digunakan pada penelitian ini adalah sumber data primer dan teknik pengumpulan data menggunakan kuesioner yang disebarkan kepada para manajer PT Pos Indonesia di Kabupaten Majalengka. Metode penelitian menggunakan metode verifikatif dengan pendekatan kuantitatif. Populasi dalam penelitian ini adalah seluruh pegawai yang berada pada tingkatan manajemen yang ada di PT Pos Indonesia daerah Kabupaten Majalengka.

\section{Hasil Penelitian dan Pembahasan}

\section{Analisis Regresi Berganda}

Tabel 1. Analisis Regresi Berganda

\begin{tabular}{|c|c|r|r|r|r|r|}
\hline \multicolumn{2}{|c|}{ Coefficients $^{\mathbf{a}}$} \\
\hline \multirow{2}{*}{ Model } & \multicolumn{2}{|c|}{$\begin{array}{c}\text { Unstandardized } \\
\text { Coefficients }\end{array}$} & $\begin{array}{c}\text { Standardized } \\
\text { Coefficients }\end{array}$ & \multirow{2}{*}{$\mathrm{t}$} & \multirow{2}{*}{ Sig. } \\
\cline { 3 - 7 } & & B & $\begin{array}{c}\text { Std. } \\
\text { Error }\end{array}$ & Beta & & \\
\hline \multirow{4}{*}{1} & (Constant) & 1.903 & 7.139 & & .267 & .792 \\
\cline { 2 - 7 } & TQM & .938 & .211 & .533 & 4.440 & .000 \\
\cline { 2 - 7 } & MK & .722 & .262 & .330 & 2.758 & .011 \\
\cline { 2 - 7 } & KO & .666 & .301 & .209 & 2.213 & .036 \\
\hline
\end{tabular}

a. Dependent Variable: KM

Sumber: Hasil Pengolahan SPSS versi 23,2021

Bersumber pada tabel analisis regresi berganda di atas, maka dapat dirumuskan persamaan regresi sebagai berikut:

$$
Y=1,903+0,938 X_{1}+0,722 X_{2}+0,666 X_{3}+e
$$

Berikut ini interpretasi dari persamaan tersebut yakni:

1. Nilai konstanta 1.903, jika variabel penerapan TQM, motivasi kerja komitmen organisasi bernilai 0 (konstan) maka kinerja manajerial akan meningkat 1.903.

2. Koefisien regresi penerapan total quality management 0,938 , mempunyai arti setiap penambahan 1 satuan pada penerapan total quality management, maka kinerja manajerial akan meningkat sebesar 0,938.

3. Koefisien regresi motivasi kerja 0,722 , mempunyai arti setiap penambahan 1 satuan pada motivasi kerja, maka kinerja manajerial meningkat sebesar 0,722.

4. Koefisien regresi komitmen organisasi 0,666, mempunyai arti setiap penambahan 1 satuan pada komitmen organisasi, maka kinerja manajerial meningkat sebesar 0,666. 


\section{Uji F}

Tabel 2. Hasil Uji Simultan (Uji F)

\begin{tabular}{|l|l|r|r|r|r|c|}
\hline \multicolumn{7}{|c|}{ ANOVA $^{\mathrm{a}}$} \\
\hline \multirow{2}{*}{ Model } & $\begin{array}{c}\text { Sum of } \\
\text { Squares }\end{array}$ & Df & $\begin{array}{c}\text { Mean } \\
\text { Square }\end{array}$ & \multicolumn{1}{c|}{ F } & Sig. \\
\hline \multirow{2}{*}{1} & Regression & 4298.238 & 3 & 1432.746 & 35.039 & $.000^{\text {b }}$ \\
\cline { 2 - 7 } & Residual & 1063.153 & 26 & 40.890 & & \\
\cline { 2 - 7 } & \multicolumn{7}{|l|}{ Total } & 5361.390 & 29 & & & \\
\hline \multicolumn{2}{|l|}{ a. Dependent Variable: KM } \\
\hline \multicolumn{2}{|l}{ b. Predictors: (Constant), KO, MK, TQM } \\
\hline
\end{tabular}

Sumber: Hasil Pengolahan SPSS versi 23,2021

Berdasarkan tabel uji simultan di atas diperoleh nilai sig. 0,000 artinya $\leq 0,05, \mathrm{H}_{0}$ ditolak. Sehingga, disimpulkan penerapan TQM (total quality management), motivasi kerja dan komitmen organisasi terdapat pengaruh yang signifikan secara simultan terhadap variabel kinerja manajerial.

\section{Uji t}

Tabel 3. Hasil Uji Parsial (Uji T)

\begin{tabular}{|c|c|c|c|c|c|c|}
\hline \multicolumn{7}{|c|}{ Coefficients $^{\mathrm{a}}$} \\
\hline & \multirow{2}{*}{ Model } & \multicolumn{2}{|c|}{$\begin{array}{l}\text { Unstandardized } \\
\text { Coefficients }\end{array}$} & \multirow{2}{*}{$\begin{array}{c}\begin{array}{c}\text { Standardized } \\
\text { Coefficients }\end{array} \\
\text { Beta }\end{array}$} & \multirow{2}{*}{$\mathrm{t}$} & \multirow{2}{*}{ Sig. } \\
\hline & & B & $\begin{array}{c}\text { Std. } \\
\text { Error }\end{array}$ & & & \\
\hline \multirow{4}{*}{1} & (Constant) & 1.903 & 7.139 & & .267 & .792 \\
\hline & TQM & .938 & .211 & .533 & 4.440 & .000 \\
\hline & MK & .722 & .262 & .330 & 2.758 & .011 \\
\hline & $\mathrm{KO}$ & .666 & .301 & .209 & 2.213 & .036 \\
\hline
\end{tabular}

a. Dependent Variable: KM

Sumber: Hasil Pengolahan SPSS versi 23,2021

1. Nilai signifikansi penerapan total quality management yakni sebesar 0,000 berarti $\leq 0,05$, dan $\mathrm{H}_{0}$ ditolak. Maka dapat disimpulkan terdapat pengaruh penerapan total quality management terhadap kinerja manajerial.

2. Nilai signifikansi motivasi kerja adalah sebesar 0,011 berarti $\leq 0,05$ dan $\mathrm{H}_{0}$ ditolak. Maka, disimpulkan terdapat pengaruh motivasi kerja terhadap kinerja manajerial.

3. Nilai signifikansi komitmen organisasi adalah sebesar 0,036 berarti $\leq 0,05$, dan $\mathrm{H}_{0}$ ditolak. Maka, disimpulkan terdapat pengaruh komitmen organisasi terhadap kinerja manajerial.

\section{Pengujian Koefisien Determinasi $\left(\mathbf{R}^{2}\right)$}

Tabel 4. Pengujian Koefisien Determinasi

\begin{tabular}{|c|c|c|c|c|}
\hline \multicolumn{5}{|c|}{ Model Summary ${ }^{b}$} \\
\hline Model & $\mathrm{R}$ & $\begin{array}{c}\mathrm{R} \\
\text { Square }\end{array}$ & $\begin{array}{c}\text { Adjusted } \\
\text { R } \\
\text { Square }\end{array}$ & $\begin{array}{l}\text { Std. Error } \\
\text { of the } \\
\text { Estimate }\end{array}$ \\
\hline 1 & $.895^{\mathrm{a}}$ & .802 & .779 & 6.39457 \\
\hline \multicolumn{5}{|c|}{ a. Predictors: (Constant), KO, MK, TQM } \\
\hline \multicolumn{5}{|c|}{ b. Dependent Variable: KM } \\
\hline
\end{tabular}

Dari tabel di atas, diperoleh nilai R sebesar 0,895 dan nilai RSquare sebesar 0,802. Hasil tersebut menunjukkan penerapan total quality management, motivasi kerja, dan komitmen organisasi memberikan pengaruh terhadap kinerja manajerial sebesar $80,2 \%$ dan sisanya $19,8 \%$ 
dipengaruhi variabel lain.

Tabel 5. Pengujian Koefisien Determinasi Parsial

\begin{tabular}{|l|l|r|r|}
\hline \multicolumn{3}{|c|}{ Coefficients $^{\mathbf{a}}$} \\
\hline \multirow{2}{*}{} & \multicolumn{1}{|c|}{$\begin{array}{c}\text { Standardized } \\
\text { Coefficients }\end{array}$} & Correlations \\
\cline { 2 - 4 } \multicolumn{2}{|c|}{ Model } & \multicolumn{1}{|c|}{ Beta } & Zero-order \\
\hline \multirow{2}{*}{1} & (Constant) & & .830 \\
\cline { 2 - 4 } & TQM & .533 & .762 \\
\cline { 2 - 4 } & MK & .330 & .515 \\
\cline { 2 - 4 } & KO & .209 & \\
\hline
\end{tabular}

Sumber: Hasil Pengolahan SPSS versi 23,2021

Berdasarkan hasil pengujian diatas dilakukan perhitungan koefisien daterminasi parsial sebagai berikut:

1. Penerapan Total Quality Management $=0,533 \times 0,830 \times 100 \%=44,2 \%$

2. Motivasi Kerja $=0,330 \times 0,762 \times 100 \%=25,2 \%$

3. Komitmen Organisasi $=0,209 \times 0,515 \times 100 \%=10,8 \%$

Dari hasil perhitungan tersebut dapat disimpulkan penerapan TQM (total quality management) memberikan pengaruh yang cukup berarti terhadap kinerja manajerial sebesar $44,2 \%$, motivasi kerja memberikan pengaruh yang cukup berarti terhadap kinerja manajerial sebesar $25,2 \%$ dan komitmen organisasi memberikan pengaruh yang rendah terhadap kinerja manajerial sebesar $10,8 \%$.

\section{Pengaruh Penerapan Total Quality Management terhadap Kinerja Manajerial}

Berdasarkan hasil pengujian hipotesis menunjukkan bahwa Penerapan Total Quality Management berpengaruh terhadap Kinerja Manajerial. Hal ini dapat dibuktikan dengan hasil uji t yang menunjukkan nilai signifikansi untuk variabel penerapan total quality management adalah sebesar $0,000 \leq 0,05$. Sehingga dapat disimpulkan $\mathrm{H}_{0}$ ditolak dan $\mathrm{H}_{\mathrm{a}}$ diterima, artinya terdapat pengaruh penerapan total quality management terhadap kinerja manajerial. Pada hasil pengujian koefisien determinasi parsial menunjukkan variabel penerapan total quality management memberikan pengaruh yang cukup berarti terhadap kinerja manajerial yaitu sebesar $44,2 \%$.

\section{Pengaruh Motivasi Kerja terhadap Kinerja Manajerial}

Hasil pengujian hipotesis menunjukkan bahwa Motivasi Kerja berpengaruh terhadap Kinerja Manajerial. Hal ini dapat dibuktikan dengan hasil uji t yang menunjukkan nilai signifikansi untuk variabel motivasi kerja adalah sebesar $0,011 \leq 0,05$. Sehingga dapat disimpulkan $\mathrm{H}_{0}$ ditolak dan Ha diterima, artinya terdapat pengaruh motivasi kerja terhadap kinerja manajerial. Pada hasil pengujian koefisien determinasi parsial menunjukkan variabel motivasi kerja memberikan pengaruh yang cukup berarti terhadap kinerja manajerial yaitu sebesar $25,2 \%$.

\section{Pengaruh Komitmen Organisasi terhadap Kinerja Manajerial}

Hasil pengujian hipotesis menunjukkan bahwa Komitmen Organisasi berpengaruh terhadap Kinerja Manajerial. Hal ini dapat dibuktikan dengan hasil uji t yang menunjukkan nilai signifikansi untuk variabel komitmen organisasi adalah sebesar $0,036 \leq 0,05$. Sehingga dapat disimpulkan $\mathrm{H}_{0}$ ditolak dan $\mathrm{Ha}$ diterima, artinya terdapat pengaruh komitmen organisasi terhadap kinerja manajerial. Pada hasil pengujian koefisien determinasi parsial menunjukkan variabel komitmen organisasi memberikan pengaruh yang masih rendah terhadap kinerja manajerial sebesar $10,76 \%$. 


\section{Kesimpulan}

Adapun dapat diambil kesimpulan dari penelitian yang dilakukan yakni:

1. Penerapan total quality management terdapat pengaruh yang signifikan secara parsial terhadap kinerja manajerial.

2. Motivasi kerja terdapat pengaruh yang signifikan secara parsial terhadap kinerja manajerial.

3. Komitmen organisasi terdapat pengaruh yang signifikan secara parsial terhadap kinerja manajerial.

\section{Acknowledge}

Terimakasih kepada pihak-pihak yang telah membantu peneliti dalam menyelesaikan penelitian ini khususnya PT Pos Indonesia di Kabupaten Majalengka, sehingga penelitian ini dapat diselesaikan tepat waktu dan baik.

\section{Daftar Pustaka}

[1] of Budget Participation and Organizational Commitment to Managerial Performance. International Journal of Economics, Business and Accounting Research (IJEBAR) Peer Reviewed - International Journal, Vol-4, Issue-2.

[2] Hasibuan, Malayu S.P. 2020. Manajemen Sumber Daya Manusia. Jakarta: PT Bumi Aksara.

[3] Juwita, Rukmi \& A. W Kusumanigrum. 2019. Pengaruh Komitmen Organisasi, Partisipasi Penyusunan Anggaran dan Akuntansi Pertanggungjawaban Terhadap Kinerja Manajerial (Studi Kasus di Direktorat Keuangan PT Pos Indonesia). Jurnal Akuntansi Tahun XI No.01

[4] Nisa, W.C \& Sapari. 2017. Pengaruh Total Quality Management, Sistem Penghargaan dan Komitmen Organisasi Terhadap Kinerja Manajerial. Jurnal Ilmu dan Riset Akuntansi, Vol.6 Nomor 11.

[5] Rahayu, Isna Rifka. 2018. Kinerja Manajemen Buruk, Karyawan Garuda Ancam Mogok Kerja, tersedia di https://www.inews.id/finance/bisnis/kinerja-manajemen-buruk-karyawangaruda-ancam-mogok-kerja [08/10/2020].

[6] Siagian, Sondang. 2008. Manajemen Sumber Daya Manusia (cetakan 15). Jakarta: Bumi Aksara.

[7] Tjiptono, Fandy \& Anastasia Diana. 2003. Total Quality Management. Yogyakarta : Andi Offset.

[8] Triamelia, E. N., Rini Lestari, dan Epi Fitriah. 2015. Pengaruh Penerapan Total Quality Management (TQM) terhadap Kinerja Manajerial (Studi Pada Perusahaan Sepatu CV. Dheraya). Prosiding Akuntansi. Volume 1, No. 2, Tahun 2015. 